\title{
Variation in Concentration of Phenolic Acid Derivatives and Quercetin Glycosides in Foliage of Cranberry that May Play a Role in Pest Deterrence
}

\author{
Catherine C. Neto and Christine A. Dao \\ Department of Chemistry and Biochemistry, University of Massachusetts Dartmouth, 285 Old \\ Westport Road, N. Dartmouth, MA 02747 \\ Michelle R. Salvas \\ University of Massachusetts Amherst, Cranberry Experiment Station, 1 State Bog Road, P.O. Box 569, \\ E. Wareham, MA 02538
}

Wesley R. Autio

Department of Plant, Soil, and Insect Sciences, University of Massachusetts Amherst, Amherst, MA 01003

\author{
Justine E. Vanden Heuvel ${ }^{1,2}$ \\ University of Massachusetts Amherst, Cranberry Experiment Station, 1 State Bog Road, P.O. Box 569, \\ E. Wareham, MA 02538
}

\begin{abstract}
AdDitional IndeX words. Vaccinium macrocarpon, gypsy moth, cranberry weevil, red-headed flea beetle
Aвstract. Several insect herbivores have been anecdotally reported to prefer 'Howes' cranberry leaves (Vaccinium macrocarpon) over those of 'Early Black'. A series of studies were undertaken to determine whether these anecdotal reports are accurate and to compare phenolic profiles in the foliage of 'Early Black' and 'Howes' for compounds that differ in concentration and could be further investigated as possible feeding deterrents. Gypsy moth larvae (Lymantria dispar) demonstrated a significant feeding preference for 'Howes' over 'Early Black'. Red-headed flea beetle adults (Systena frontalis) demonstrated a similar but not statistically significant trend, whereas cranberry weevil (Anthonomus musculus) did not prefer either cultivar. Compounds giving rise to six peaks in the phenolic profile were significantly greater in concentration in 'Early Black' than 'Howes' on at least one of three sampling dates during the growing season. Five of these compounds were isolated from leaves harvested at the June time point coinciding with gypsy moth infestation and identified as: 5-O-caffeoylquinic acid, 3-O-p-coumaroylquinic acid, 5-Op-coumaroylquinic acid, quercetin-3-O-galactoside, and quercetin-3-O-rhamnoside.
\end{abstract}

The american cranberry is a fruit grown commercially in a wetland setting in Massachusetts, Wisconsin, New Jersey, Washington, and Oregon (Eck, 1990). The low-growing nondeciduous vine covers bog floors, forming a dense mat. Fruit is borne on short, vertical stems known as uprights.

The production regions of Massachusetts and New Jersey have pest pressure from both insects and diseases (Averill and Sylvia, 1998). Foliage feeders in cranberry production include cutworms (Lepidoptera: Noctuidae), spanworms (Lepidoptera: Geometridae), fireworms (Lepidoptera: Tortricidae), and a flea beetle (Coleoptera: Chrysomelidae) (Averill and Sylvia, 1998). Injury by these pests can be extensive with respect to loss of vegetative tissue (Averill and Sylvia, 1998). For example, larvae of the black-headed fireworm (Rhopobota naevana) skeletonize leaves, resulting in large areas of the bog having a burnt appearance (Averill and Sylvia, 1998). Red-headed flea beetle adults feed on the underside of leaves, consuming tissue

Received for publication 23 Dec. 2009. Accepted for publication 16 Sept. 2010. We thank Amber Awad, Martha Sylvia, and Anne Averill for their assistance with this work and Joan Davenport for her review of the manuscript.

${ }^{1}$ Current address: Department of Horticultural Sciences, Cornell University, Geneva, NY 14456 and Department of Horticulture, Cornell University, Ithaca, NY 14850.

${ }^{2}$ Corresponding author. E-mail: jev32@cornell.edu. while leaving the veins (Averill and Sylvia, 1998). This type of damage can significantly reduce vine productivity and hence fruit production (Averill and Sylvia, 1998) through reduction in photosynthetically active leaf area. As a result of the perennial nature of cranberry, damage by these pests can have a significant negative effect in the next season. To avoid large yield losses, the cranberry industry often must implement management tactics such as pesticide applications to reduce populations of foliage and fruit feeders (Averill and Sylvia, 2005).

Interestingly, entomologists have reported that several foliage feeders of cranberry in Massachusetts exhibit cultivar preferences with respect to feeding. Fire beetle (Cryptocephalus incertus), cranberry tipworm (Dasineura oxycoccana), spotted cutworm (Xestia spp.), black-headed fireworm, and flea beetle have all been anecdotally reported by growers and extension personnel (see reports in Averill and Sylvia, 1998) to preferentially feed on 'Howes' rather than 'Early Black'. However, these observations have never been confirmed through controlled studies.

Data available from other species suggest that feeding preferences of pests may be the result of differing phenolic profiles and/or concentrations in vegetative tissues. For example, Beninger and Abou-Zaid (1997) suggest that gypsy moths, a destructive pest of cranberry (Averill and Sylvia, 1998), do not feed on Pinus species as a result of the presence of flavonol 
glycosides. The composition of phenolic acids in cranberry leaves has not been reported in the literature, although the phenolic composition of leaves of related species Vaccinium myrtillus (Witzell et al., 2003) and Vaccinium darrowi (Ranger et al., 2007) has been investigated, and the seasonal variation in flavonoid composition in cranberry fruit has been documented (Vvedenskaya and Vorsa, 2004).

If the reported preferences of insect herbivores for 'Howes' cranberry vines are accurate (Averill and Sylvia, 1998), then a comparison of phenolic profiles between cranberry cultivars is warranted to determine the chemical cause of these feeding preferences. If a feeding deterrent(s) is identified, breeding schemes and/or cultural practices can be investigated to increase the presence/concentration of such compounds in the leaves and/or fruit.

Our objectives for this project were to determine whether insect herbivores have a feeding preference for 'Howes' or 'Early Black' cranberry leaves, to investigate the phenolic profiles in the foliage of those two cranberry cultivars at intervals throughout the growing season that coincided with infestation, and then to isolate and identify compounds that differed between the two cultivars.

\section{Materials and Methods}

\section{Feeding studies}

Feeding bioassays were conducted in 2006 to determine the feeding preferences of three cranberry pests. Gypsy moth larvae (third instar), cranberry weevil adults, and red-headed flea beetle were studied in late June, early July, and early August, respectively, when they were at their most active on the bog. Gypsy moth larvae were collected from an abandoned 'Early Black' bog in Carver, MA, cranberry weevil adults were collected from multiple bogs of 'Early Black' and 'Stevens' in and around Wareham, MA, and red-headed flea beetle were collected from a 'Stevens' bog in Middleboro, MA. All pests were feeding on cranberry at the time of collection and were placed into the feeding studies within $3 \mathrm{~d}$ of collection. Before initiation of the studies, the pests were held in clear plastic containers with air holes at room temperature $\left(\approx 22{ }^{\circ} \mathrm{C}\right)$ and were fed fresh cranberry uprights. These pests were chosen for study because they attack cranberry at different times in the growing season (gypsy moth in late June, cranberry weevil in early July, and red-headed flea beetle in early August).

For all three experiments, a single insect was placed into each of 32 covered $55 \times 33 \times 30$-mm plastic cells. Filter paper moistened with $400 \mu \mathrm{L}$ of tap water was added to each cell. Each cell contained $4 \mathrm{~cm}$ of new growth of 'Howes' and 'Early Black' uprights (i.e., short vertical stems), which was collected on the first day of the experiment from uprights removed from potted vines growing under fully exposed conditions outside. Cultivars were randomized with respect to position in cells and were marked with colored laboratory tape for identification purposes.

The cells containing the insects and uprights were placed in growth chambers (PGC-10; Percival Scientific, Perry, IA) at varying conditions based on the outside ambient temperature and daylight hours at the time of the experiment. For the gypsy moth and cranberry weevil, the growth chambers were set to $14.5 \mathrm{~h}$ of light at $22^{\circ} \mathrm{C}$ with a night temperature of $17^{\circ} \mathrm{C}$. The flea beetles were kept at $25^{\circ} \mathrm{C}$ during the 13.25 -h day and $17{ }^{\circ} \mathrm{C}$ at night. Light was provided at $\approx 700 \mu \mathrm{mol} \cdot \mathrm{m}^{-2} \cdot \mathrm{s}^{-1}$. The gypsy moth larvae were allowed to feed for $24 \mathrm{~h}$, the cranberry weevil for $72 \mathrm{~h}$, and the flea beetle for $5 \mathrm{~d}$ with the duration of feeding determined by the length of time that passed before considerable visual damage was noted on the uprights. At the conclusion of the experiment, uprights were visually assessed for feeding damage using a lighted binocular system and ranked based on leaf injury as having no visible feeding (scored as 0 ), light feeding [less than 30\% of leaf area affected (scored as 1)], medium feeding [ $30 \%$ to $60 \%$ of leaf area affected (scored as 2)], or heavy feeding [greater than $60 \%$ of leaf area affected (scored as 3 )].

\section{Reagents}

Solvents for sample extraction and high-performance liquid chromatography (HPLC) analysis including HPLC-grade methanol and water were purchased from Pharmco Products (Brookfield, CT). Reagents used as HPLC and mass spectrometry (MS) standards were obtained as follows: p-hydroxycinnamic (p-coumaric) acid (HCA), caffeic acid, chlorogenic (3-Ocaffeoylquinic) acid, (-)epicatechin, quercetin-3-O-rhamnoside (quercitrin), and quercetin-3-O-glucoside (isoquercetin) were purchased from Sigma-Aldrich (St. Louis, MO). Quercetin-3O-galactoside was purchased from Chromadex (Irvine, CA).

\section{Analysis of leaf extracts}

New growth (i.e., current-year growth) was collected from 'Early Black' and 'Howes' uprights growing on State Bog at the University of Massachusetts Amherst Cranberry Station, East Wareham, MA on 16 June, 20 July, and 17 Aug. 2006. Four hundred uprights per cultivar (new growth only) were collected for each sampling date. On returning to the laboratory, leaves were removed from the stems and were subsequently flashfrozen in liquid nitrogen. The leaves were ground to a fine powder in a mortar and pestle with liquid nitrogen and then lyophilized. The powder was stored at $-20^{\circ} \mathrm{C}$ until subsampling and analysis. For each sampling date, three subsamples of 150 $\mathrm{mg}$ of each cultivar were analyzed. A second sampling of 'Early Black' was collected in June 2008 at the same site to provide further material for isolation of phenolics; plant material was frozen, ground, and stored as described previously.

High-performance liquid chromatography analysis was used to determine phenolic acid derivatives, catechins, and flavonol glycosides in the leaf samples. Using a method similar to Witzell et al. (2003), 150-mg samples of lyophilized ground leaf tissue were extracted with $5 \mathrm{~mL}$ of 50:25:24:1 methanol: acetone:water:formic acid. The samples were shaken for $2 \mathrm{~min}$, centrifuged for $10 \mathrm{~min}$, and the supernatant was transferred to a round-bottomed flask. The extracted pellet was re-extracted with $2.5 \mathrm{~mL}$ of 50:25:24:1 methanol:acetone:water:formic acid in the same manner as previously described, after which the supernatants were combined and evaporated to dryness using a rotary evaporator. The dried samples were reconstituted using $2 \mathrm{~mL} \mathrm{50 \%} \mathrm{aqueous} \mathrm{methanol} \mathrm{and} \mathrm{syringe-filtered} \mathrm{through}$ a $0.45-\mu \mathrm{m}$ filter before $20-\mu \mathrm{L}$ injection into the HPLC system.

Phenolic compounds known to be present in cranberry fruit include p-hydroxycinnamic or p-coumaric acid, caffeic acid, epicatechin, and quercetin-3-galactoside (Lees and Francis, 1971; Zuo et al., 2002). A mixture of these compounds was prepared at $0.5 \mathrm{~mm}$ concentration in methanol for HPLC analysis. They were also prepared in serial dilution to determine standard curves.

Extracts were initially analyzed using a Waters' HPLC-diode array detector (DAD) binary system with a 996 photodiode 
array detector and Millenium Software (Waters, Milford, MA) at ambient temperature $\left(20{ }^{\circ} \mathrm{C}\right)$ with a reversed-phase Waters C18 Symmetry column $(4.6 \times 150 \mathrm{~mm}, 5-\mu \mathrm{m}$ particle size $)$. Gradient separation with mobile phases A, aqueous $1 \%$ acetic acid, and B, methanol:aqueous 1\% acetic acid 40:60 (v/v) at a flow rate of $1 \mathrm{~mL} \cdot \mathrm{min}^{-1}$ was as follows: $15 \%$ to $20 \% \mathrm{~B}$ from 0 to $5 \mathrm{~min}$, to $35 \% \mathrm{~B}$ at $15 \mathrm{~min}$, to $60 \% \mathrm{~B}$ at $35 \mathrm{~min}$, to $75 \% \mathrm{~B}$ at $45 \mathrm{~min}$, to $100 \% \mathrm{~B}$ at $55 \mathrm{~min}$ followed by a 20 -min column reequilibration. The $\lambda$ max for each peak was recorded. Tentative identifications of several compounds in the 'Early Black' extracts were later verified by HPLC analysis of the extract in the presence of internal standards. Identification of the major quercetin glycosides in the leaf extracts was initially based on comparison of the ultraviolet-visible profiles and order of elution with previously reported analysis of quercetin glycosides in the fruit (Yan et al., 2002). This elution order also agreed with that reported in cranberry powder (Vvedenskaya and Vorsa, 2004). Those peaks identified as present in higher quantity in 'Early Black' were further confirmed by HPLC analysis with commercially obtained quercetin glycosides as internal standards.

Phenolic acid derivatives, catechins, and flavonol glycosides with a threshold peak area greater than $0.31 \%$ (from 0 to $5 \mathrm{~min}$ and 35 to $70 \mathrm{~min}$ ) and greater than $1.2 \%(10$ to $35 \mathrm{~min})$ at $280 \mathrm{~nm}$ were tentatively classified according to their $\lambda$ maximum as HCA epicatechin-based tannins or quercetin derivatives. They were quantified as HCA equivalents, epicatechin equivalents, or quercetin galactoside equivalents at detection wavelengths of 310,280 , and $355 \mathrm{~nm}$, respectively, by the standard curve method using a similar Waters HPLC system with a dualwavelength absorbance detector, Empower software (Version 5; Waters), and the same C18 Symmetry column.

ISOLATION AND IDENTIFICATION OF HYDROXYCINNAMIC AND CAFFEIC ACID DERIVATIVES AND FLAVONOL GLYCOSIDES FROM 'EARLY Black'. Four compounds with absorbance maxima characteristic of phenolic acid derivatives and two compounds with characteristics of quercetin glycosides were identified as being present in higher quantity in the 'Early Black' by HPLC. These six compounds were targeted for identification. 'Early Black' foliage was harvested in June 2008; extraction and analysis as described previously confirmed the presence of these compounds. A larger-scale extraction, separation, and isolation by semipreparative HPLC followed. A total of $12.0 \mathrm{~g}$ of leaves was soaked in $200 \mathrm{~mL}$ distilled water for $2 \mathrm{~h}$ and then blended with $250 \mathrm{~mL}$ of extraction solvent, 40:40:19:1 methanol:acetone:distilled water:formic acid. The mixture was filtered and the solids re-extracted with another $250-\mathrm{mL}$ portion of extraction solvent; filtrates were combined and concentrated by rotary evaporation followed by freeze-drying to yield $2.1513 \mathrm{~g}$ of crude extract. The crude extract was then dissolved in $500 \mathrm{~mL}$ distilled water and extracted $3 \times$ with $300-\mathrm{mL}$ portions of ethyl acetate. The water extract was freeze-dried to yield $1.282 \mathrm{~g}$; the ethyl acetate layer dried by rotary evaporation to yield $0.718 \mathrm{~g}$. HPLC analysis by the program described previously showed that the aqueous extract contained mainly tannins and phenolic acids, whereas the ethyl acetate extract contained some tannins and the flavonol glycosides. The aqueous extract was further fractionated on Sephadex LH-20 $(2.5 \times 20 \mathrm{~cm}$; GE Healthcare, Uppsala, Sweden) eluting with increasing methanol in water $(15 \%, 50 \%, 70 \%$ methanol) and then $70 \%$ acetone. This produced four fractions. HPLC analysis showed the first fraction (15:85 methanol: $\mathrm{H}_{2} \mathrm{O}, 218 \mathrm{mg}$ ) contained the phenolic acid derivatives to be identified, and the second and third fractions contained the flavonol glycosides.

All extracts and fractions were analyzed on the HPLC-DAD system described previously using a reversed phased Waters Symmetry $\mathrm{C}_{18}$ column $(4.6 \times 150 \mathrm{~mm})$ and a photodiode array detector monitored at 210 to $600 \mathrm{~nm}$. The program used a binary solvent gradient: solvent $\mathrm{A}$ was $2 \%$ aqueous acetic acid and solvent $\mathrm{B}$ was 40:60 (2\% acetic acid/methanol) with a flow rate of $0.8 \mathrm{~mL} \cdot \mathrm{min}^{-1}$ : 0 to $5 \mathrm{~min}, 15 \%$ to $20 \% \mathrm{~B} ; 5$ to $15 \mathrm{~min}, 20 \%$ to $60 \% \mathrm{~B} ; 15$ to $35 \mathrm{~min}, 60 \%$ to $75 \% \mathrm{~B}$; and 35 to $45 \mathrm{~min}, 75 \%$ to $100 \% \mathrm{~B}$.

Four peaks were identified in the 15:85 methanol: $\mathrm{H}_{2} \mathrm{O}$ fraction by their retention time and ultraviolet-visible spectral characteristics as the same compounds present in the previously analyzed 2006 'Early Black' extracts. The numbering of these compounds reflects the original peak numbers assigned in the 2006 extracts (Peaks 4, 7, 13, and 16). These compounds were isolated by preparative HPLC on $150 \mathrm{mg}$ of the fraction. The column was a Novapak reversed phase $\mathrm{C}_{18}(7.8 \times 300 \mathrm{~mm}$; Waters). The preparative HPLC program used the same solvents and gradient as described previously but at a flow rate of $1.5 \mathrm{~mL} \cdot \mathrm{min}^{-1}$. The eluent from these peaks was collected and dried in 1 to $3 \mathrm{mg}$ quantities by rotary evaporation/lyophilization, providing enough sample for MS analysis. Separation of the 50:50 methanol: $\mathrm{H}_{2} \mathrm{O}$ fraction using the same program described previously yielded two additional compounds, which matched the retention time and absorbance maxima of the quercetin glycosides (Peaks 23 and 29) targeted for identification. These were also collected for MS analysis.

The isolated compounds were analyzed by electrospray ionization (ESI)-MS on a mass spectrometer (Sciex API 150EX Turbo Ion Spray; Applied Biosystems, Foster City, CA) equipped with a Harvard Apparatus injector (Holliston, MA) and Analyst software. All samples, including p-hydroxycinnamic (p-coumaric) and chlorogenic acid (3-O-caffeoylquinic acid) standards, were dissolved in $300 \mu \mathrm{L}$ of liquid chromatographyMS grade water and analyzed in positive and/or negative ion mode.

\section{Statistical analysis}

Analyses of variance of the insect data were conducted with the CATMOD procedure (Stokes et al., 1995) of SAS (Version 9; SAS Institute, Cary, NC). Specifically, differences between cultivars were assessed with respect to ratings of feeding damage. Analyses of variance for the phenolic concentration studies were conducted with the GLM procedure of SAS (Littell et al., 2002). The analysis model included cultivar, sample date, and the interaction of the two. Where interactions were significant, the slice option of the least square means statement was used to separate the interaction into the effects of cultivar within sample date.

\section{Results}

Feeding studies. A significant preference by gypsy moth larvae for the cultivar Howes was evident. After $24 \mathrm{~h}$ of feeding, 15 uprights of 'Howes' showed either medium or heavy feeding damage compared with only one upright of 'Early Black' (Table 1). The average feeding score was 1.28 for 'Howes' compared with 0.63 for 'Early Black' $(P=0.0009)$. Cranberry weevil did not demonstrate a feeding preference (Table 1), and a non-significant trend for flea beetles to prefer 'Howes' was 
Table 1. Feeding damage on new growth of 'Howes' and 'Early Black' (EB) cranberry uprights by three insect pests.

\begin{tabular}{|c|c|c|c|c|c|c|c|c|}
\hline \multirow[b]{2}{*}{ Insect } & \multirow[b]{2}{*}{ Cultivar } & \multirow[b]{2}{*}{ Time } & \multicolumn{4}{|c|}{ Uprights (no.) exhibiting ${ }^{z}$} & \multirow[b]{2}{*}{ Avg score ${ }^{z}$} & \multirow[b]{2}{*}{$P$ (cultivar) } \\
\hline & & & No feeding & Light feeding & Medium feeding & Heavy feeding & & \\
\hline \multirow[t]{2}{*}{ Gypsy moth } & Howes & \multirow[t]{2}{*}{$24 \mathrm{~h}$} & 9 & 8 & 12 & 3 & 1.28 & \multirow[t]{2}{*}{0.0009} \\
\hline & EB & & 13 & 18 & 1 & 0 & 0.63 & \\
\hline Cranberry weevil & EB & & 6 & 15 & 9 & 2 & 1.22 & 0.2353 \\
\hline \multirow[t]{2}{*}{ Flea beetle } & Howes & $5 \mathrm{~d}$ & 1 & 10 & 17 & 4 & 1.75 & \multirow[t]{2}{*}{0.0532} \\
\hline & EB & & 6 & 14 & 7 & 5 & 1.34 & \\
\hline
\end{tabular}

${ }^{\mathrm{Z}}$ Uprights were scored as having no visible feeding (scored as 0), light feeding [less than $30 \%$ of leaf area affected (scored as 1)], medium feeding $[30 \%$ to $60 \%$ of leaf area affected (scored as 2)], or heavy feeding [greater than $60 \%$ of leaf area affected (scored as 3 )].

noticeable $(P=0.0532)$. After $5 \mathrm{~d}$ of feeding by flea beetles, 21 uprights of 'Howes' showed either medium or heavy feeding damage compared with 12 uprights of 'Early Black' showing that amount of damage (Table 1). Additionally, six uprights of 'Early Black' had no visible feeding damage at the end of the experiment compared with only one upright of 'Howes'.

LEAF EXTRACTS. Approximately 34 quantifiable peaks were visible in the phenolic profiles of 'Early Black' and 'Howes' leaves at 280 $\mathrm{nm}$ (data not shown). Six peaks in the chromatogram stood out visibly as differing in area between the 'Early Black' and 'Howes' samples. Of those six peaks, all were evident at $310 \mathrm{~nm}$ (Fig. 1), and Peaks 23 and 29 were also strongly absorbing at $355 \mathrm{~nm}$ (data not shown). Probability values for differences in concentration of these compounds between cultivars and among dates are presented in Table 2.

The $\lambda_{\max }$ values for Peaks 4 and 7 of the original HPLC are shown in Table 3. The absorbance maxima
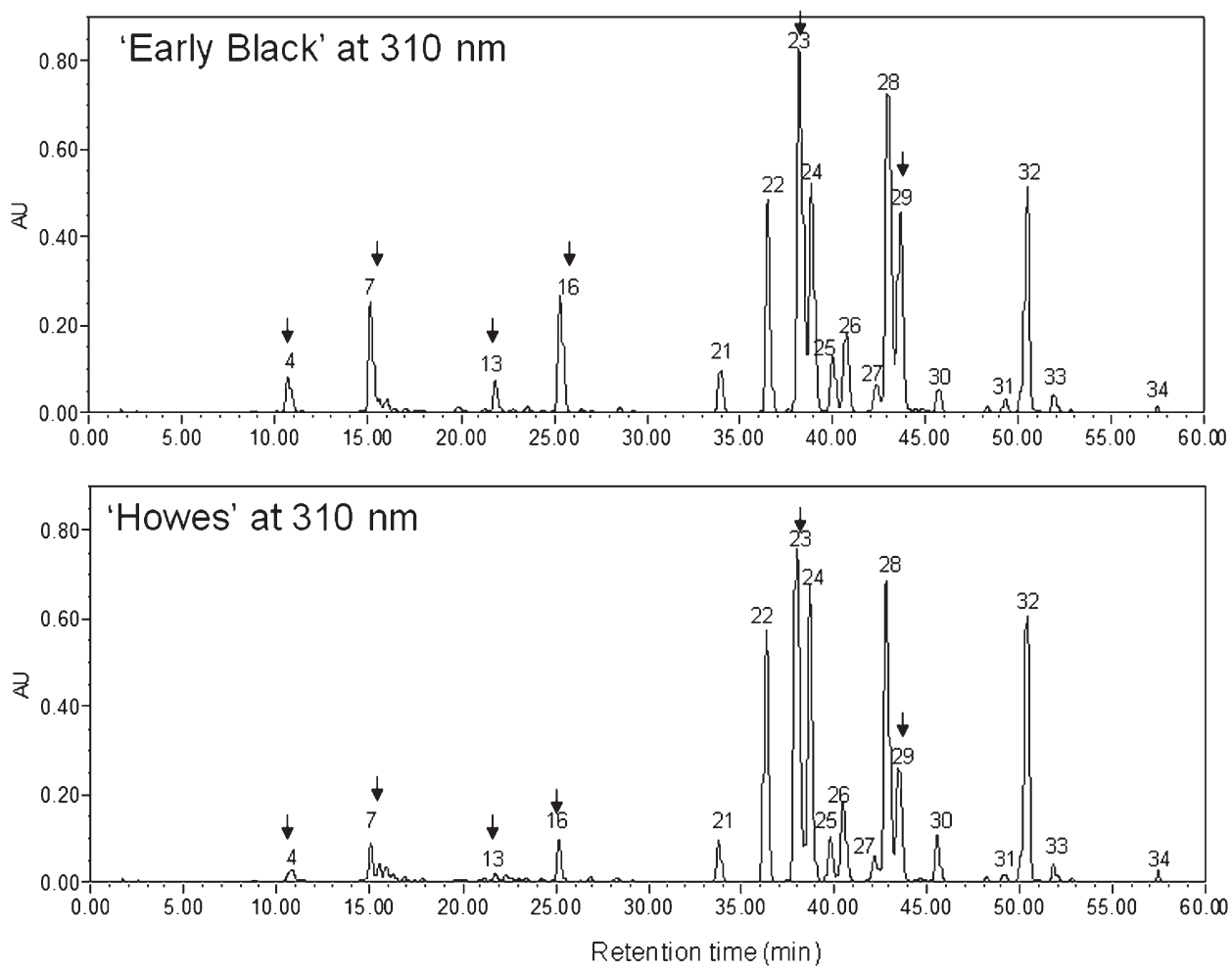

Fig. 1. Chromatograms of extracts of 'Early Black' and 'Howes' cranberry leaves at $310 \mathrm{~nm}$ (June sampling). Arrows indicate compounds with concentrations greater in 'Early Black' on at least one of three sampling dates. $\mathrm{AU}=$ absorbance units.

between 315 and $325 \mathrm{~nm}$ were suggestive of either HCA or caffeic acid derivatives. The compound giving rise to Peak 4, when quantified as HCAequivalents, was a minimum of $50 \%$ higher in concentration in the leaves of 'Early Black' than in 'Howes' (Table 3) on all three dates of measurement. The compound giving rise to Peak 7 was $\approx 370 \%$ higher in 'Early Black' leaves compared with 'Howes' leaves in June, but in July, the concentration of this compound was higher in 'Howes', and by August, there was no significant difference between the cultivars (Table 3). These two peaks were subsequently observed in a fraction of 'Early Black' foliage extract (harvested in June 2008). Isolation and ESI-MS analysis of the two compounds were suggestive of caffeic acid derivatives. Fragment masses are shown in Table 4. Both contain fragments in the negative ion mode at $\mathrm{m} / \mathrm{z}=353$ and 191, matching the authentic chlorogenic acid standard and data reported by Nandutu et al. (2007). However, neither Peak 4 nor 7 coeluted with the standard. Compound 4 showed an additional peak at $\mathrm{m} / \mathrm{z}=371$ in the negative ion mode (mass of
372) for which we could not find a match in the literature. Compound 4 is tentatively assigned as a caffeic acid derivative, but there may have been a contaminant present. The molecular ion and fragments for Compound 7 matched those reported in the literature for 5-O-caffeoylquinic acid, an isomer of chlorogenic acid previously identified in foliage from the wild blueberry, $V$. darrowi (Ranger et al., 2007).

Peak 13 had $\lambda_{\max }$ values indicative of a hydroxycinnamic acid derivative. Concentrations did not differ significantly between cultivars in June and July, but in August, the concentration of this compound in 'Early Black' leaves was $28 \%$ greater than in 'Howes' (Table 3). This compound was also subsequently identified in another 'Early Black' foliage extract and isolated as Compound 13. Results of ESI-MS analysis are shown in Table 4. The fragmentation pattern in the negative ion mode of $[\mathrm{M}-\mathrm{H}]=337,191,161,119$ closely matched data reported by Ranger et al. (2007). Thus, Compound 13 was identified as 3-O-p-coumaroylquinic acid. 
Table 2. Summary of analysis of variance table for concentration of phenolic compounds in 'Early Black' and 'Howes' cranberry leaf extracts.

\begin{tabular}{lrrrrrr}
\hline & \multicolumn{5}{c}{ Probability value } \\
\cline { 2 - 7 } Source & Peak 4 & Peak 7 & Peak 13 & Peak 16 at 280 nm & Peak 16 at 310 nm & Peak 23 \\
\hline Cultivar & $<0.0001$ & 0.6762 & 0.7720 & $<0.0001$ & $<0.0001$ & 0.5999 \\
Date & 0.0003 & $<0.0001$ & 0.6790 & 0.8876 & 0.0050 & 0.0026 \\
Cultivar $\times$ date & 0.0024 & $<0.0001$ & 0.0049 & 0.3067 & 0.1424 & 0.0002 \\
\hline
\end{tabular}

${ }^{\mathrm{z}}$ Descriptions of peaks are available in Table 3.

Table 3. Retention time, $\lambda$ maximum, probability values (cultivar), and concentration (hydroxycinnamic acid equivalents or quercetin galactoside equivalents) of possible insect feeding deterrents in 'Early Black' and 'Howes' cranberry leaf extracts.

\begin{tabular}{|c|c|c|c|c|c|c|c|}
\hline Peak no. & $\begin{array}{l}\text { Retention } \\
\text { time (min) }\end{array}$ & $\begin{array}{c}\lambda \text { Maximum } \\
(\mathrm{nm})\end{array}$ & Tentative identification & $\begin{array}{l}\text { Sample } \\
\text { date }\end{array}$ & $\begin{array}{c}P \\
\text { (cultivar) }\end{array}$ & $\begin{array}{c}\text { Concn in } \\
\text { 'Early Black' } \\
\left(\mathrm{mg} \cdot \mathrm{g}^{-1}\right)\end{array}$ & $\begin{array}{l}\text { Concn in } \\
\text { 'Howes' } \\
\left(\mathrm{mg} \cdot \mathrm{g}^{-1}\right)\end{array}$ \\
\hline \multirow[t]{2}{*}{4} & 10.72 & $232.1,314.8$ & Caffeic acid derivative & June & $<0.0001$ & 0.029 & 0.004 \\
\hline & & & & August & $<0.0001$ & 0.027 & 0.000 \\
\hline \multirow[t]{2}{*}{7} & 15.14 & $234.4,325.5$ & 5-O-p-caffeoylquinic acid & June & $<0.0001$ & 0.108 & 0.023 \\
\hline & & & & July & 0.0004 & 0.123 & 0.185 \\
\hline \multirow[t]{3}{*}{13} & 21.27 & $232.1,306.5$ & 3-O-p-coumaroylquinic acid & June & 0.3307 & 3.12 & 3.35 \\
\hline & & & & July & 0.0720 & 2.90 & 3.36 \\
\hline & & & & August & 0.0044 & 3.67 & 2.86 \\
\hline \multirow[t]{3}{*}{16} & 25.35 & $233.3289(\mathrm{sh}), 311.2$ & 5-O-p-coumaroylquinic acid & June & 0.0008 & 3.20 & 1.94 \\
\hline & & & & July & 0.0032 & 3.09 & 2.05 \\
\hline & & & & August & 0.0489 & 2.97 & 2.35 \\
\hline & & & & July & 0.0139 & 1.94 & 1.55 \\
\hline & & & & August & 0.0192 & 2.13 & 1.76 \\
\hline
\end{tabular}

sh $=$ shoulder

Table 4. Electrospray ionization-mass spectrometry (ESI-MS) data and identification of phenolic acid and quercetin derivatives isolated from 'Early Black' cranberry leaf extract.

\begin{tabular}{|c|c|c|c|c|}
\hline $\begin{array}{l}\text { HPLC } \\
\text { peak no. }\end{array}$ & $\begin{array}{l}\lambda \text { Maximum } \\
(\mathrm{nm})\end{array}$ & $\begin{array}{c}\text { Deprotonated molecular ion [M-H] } \\
\text { and fragmentation in ESI-MS }\end{array}$ & $\begin{array}{c}\text { Protonated molecular ion }[\mathrm{M}+\mathrm{H}]^{+} \\
\text {and fragmentation in ESI-MS }\end{array}$ & Tentative identification \\
\hline 4 & $236.8,317.2$ & $371,353,191,179$ & Not detected (ND) & Caffeic acid derivative \\
\hline 7 & $234.4,325.5$ & $353,191,179,161,128$ & ND & 5-O-caffeoylquinic acid \\
\hline 16 & $233.3,311.2$ & 337,161 & $339,193,163,129$ & 5-O-p-coumaroylquinic acid \\
\hline 23 & $255.6,354.1$ & 463,301 & ND & Quercetin-3-O-galactoside \\
\hline 29 & $256.8,349.3$ & 447,301 & ND & Quercetin-3-O-rhamnoside \\
\hline
\end{tabular}

HPLC $=$ high-performance liquid chromatography.

A compound eluting at $25.35 \mathrm{~min}$ (Peak 16) appeared in both the 'Early Black' and 'Howes' leaves. $\lambda_{\max }$ values were indicative of a derivative of HCA. 'Early Black' leaves contained a higher concentration of the observed compound throughout the season than 'Howes' leaves (Table 3). Compound 16 was subsequently isolated from 'Early Black' foliage by preparative HPLC. ESI-MS data for 16 is shown in Table 4. A fragmentation pattern in the positive ion mode of $[\mathrm{M}+\mathrm{H}]=$ 339, 193, 163, 129 and Peaks at 337 and 161 in the negative ion mode were observed. Both patterns are consistent with MS data reported in the literature (Ranger et al., 2007) for 5-Op-coumaroylquinic acid. Thus, Compounds 13 and 16 are tentatively identified as quinic acid esters of p-coumaric (p-hydroxycinnamic) acid. These compounds are not available commercially for use as internal standards; however, we are confident in our assignments based on comparison with MS data previously reported in Vaccinium.

The compounds eluting from Peaks 23 and 29 had $\lambda_{\max }$ values indicative of quercetin glycosides (Table 3 ). The quercetin glycoside in 23 was found at a higher concentration in 'Early Black' leaves in June but higher in 'Howes' leaves in July (Table 3). The quercetin glycoside in 29 was found at a much greater concentration in 'Early Black' leaves on all three sampling dates (Table 3). Based on the identification and elution pattern of quercetin glycosides in cranberry fruit (Vvedenskaya et al., 2004; Yan et al., 2002), these two glycosides were identified as quercetin-3-O-galactoside (Peak 23) and quercetin-3-O-rhamnoside (Peak 29). This was further 
confirmed by analysis of the 'Early Black' leaf extract in the presence of commercially obtained quercetin-3-O-galactoside, quercetin-3-O-glucoside, and quercetin-3-O-rhamnoside as internal standards. The area of 23 increased in the presence of the quercetin-3-O-galactoside standard, whereas the glucoside standard eluted $0.6 \mathrm{~min}$ later. The quercetin-3-O-rhamnoside standard matched 29. MS analysis in negative ion mode showed fragments at 463 and $301 \mathrm{~m} / \mathrm{z}$ for 23 , and 447 and $301 \mathrm{~m} / \mathrm{z}$ for 29 , which are consistent with a quercetin hexoside and pentoside, respectively.

\section{Discussion}

Comparison of the phenolic profiles of 'Early Black' and 'Howes' leaves through the growing season suggested the possibility of six compounds that warrant further investigation as possible insect-feeding deterrents. Based on ultraviolet absorbance characteristics, comparison with internal reference standards by HPLC, and MS data, five of the six compounds were identified. The compounds are p-coumaroyl and caffeoyl quinic acid isomers and two quercetin glycosides (Fig. 2). These are members of phytochemical classes that are well documented to be feeding deterrents to insect species in other crops (Ayres et al., 1997; Beninger and Abou-Zaid, 1997; Simmonds et al., 1990). This is the first report of these compounds in foliage of cranberry, although several of these compounds have been identified in the foliage of a wild blueberry species (Ranger et al., 2007).

Gypsy moth larvae preferentially fed on 'Howes' over 'Early Black'. Three phenolic acids as well as two quercetin glycosides were produced in significantly higher concentrations in 'Early Black' compared with 'Howes' at the June sampling. Rutin and quercetin-3-O-glucoside isolated from several Pinus species as well as the aglycone quercetin were incorporated into the diet in controlled feeding trials with early instar gypsy moth larvae and found to strongly inhibit growth and increase mortality (Beninger and Abou-Zaid, 1997). Because both quercetin-3-O-galactoside and quercetin-3-O-rhamnoside were significantly greater in concentration in 'Early Black' compared with 'Howes' at the June sampling, they may explain why the gypsy moth preferred 'Howes' as a host during its larval stages, because Lepidoptera have taste receptors that respond to phenolics (Simmonds et al., 1990). Beninger and Abou-Zaid (1997) suggest several mechanisms by which the aglycone quercetin reduces growth of lepidopteran larvae, including

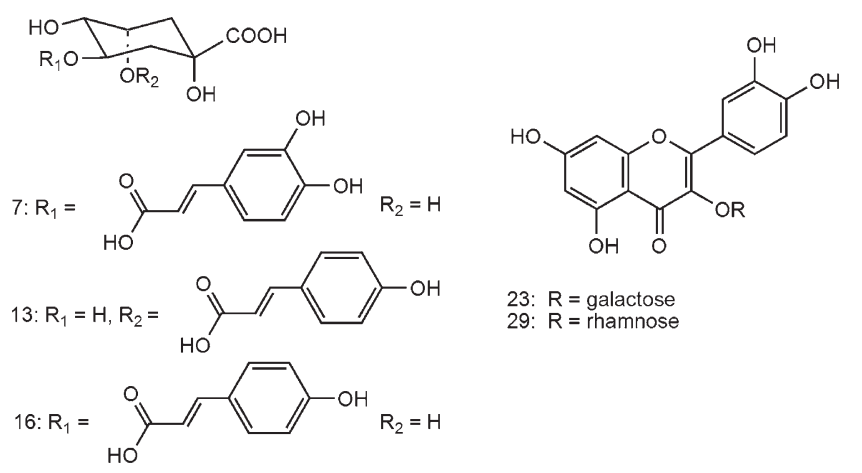

Fig. 2. Structures of compounds isolated from extracts of 'Early Black' cranberry leaves: (4) unidentified caffeic acid derivative, (7) 5-O-caffeoylquinic acid, (13) 3-O-p-coumaroylquinic acid, (16) 5-O-p-coumaroylquinic acid, (23) quercetin-3-O-galactoside, (29) quercetin-3-O-rhamnopyranoside. inhibition of cytochrome P-450-dependent ecdysone 20-monooxygenase, mitochondrial ATPase, and phodiesterase in the gut.

Although cranberry weevil did not indicate a feeding preference between cultivars, flea beetles demonstrated a nonsignificant preference for 'Howes' when feeding preference studies were conducted in August. At the August sampling, three phenolic acids as well as quercetin-3-0-rhamnoside were found at significantly greater concentrations in 'Early Black' compared with 'Howes'. Unfortunately, little information is available on feeding deterrents in skeletonizing flea beetles, suggesting that all four compounds found at higher concentrations in 'Early Black' in August should be further investigated. Previous reports of condensed tannins from other plants differ in their findings with regard to potential roles in defense against herbivores (Ayres et al., 1997). Chlorogenic acid or phenols in general did not appear to play a central role in resistance of Coffea arabica leaves to coffee leaf miner [Leucoptera coffeella (Ramiro et al., 2006)], but caffeoylquinic acids from wild groundnuts (Arachis paraguariensis) were potent inhibitors of larval development of cotton bollworm [Helicoverpa armigera (Kimmins et al., 1995)] and tobacco cutworm [Spodoptera litura (Stevenson et al., 1993)]. Conversely, a ragweed leaf extract containing caffeoylquinic acids mixed with triterpenoids $\alpha$ and $\beta$-amyrin was reported to stimulate feeding of the leaf beetle [Ophraella communa (Tamura et al., 2004)]. The effects of such compounds on insect viability and behavior are complex and may depend on both the organism and the presence of other compounds.

Concentration of many of the identified phenolic compounds in the leaf tissue varied over the course of the growing season, likely attributable in part to elongation of the upright (including increased inclusion in the earlier samplings of expanding or recently expanded leaves) and changes in upright nitrogen concentration. The carbon:nitrogen ratio of cranberry uprights increases as the growing season progresses and upright nitrogen decreases (Vanden Heuvel and Davenport, 2006), likely playing a significant role in phenolic concentration and hence attractiveness to herbivores. In alaska paper birch (Betula papyrifera ssp. humilis), nitrogen fertilization reduced total phenols, condensed tannin, and papyriferic acid resulting in increased biomass consumption by snowshoe hares [Lepus americanus (Bryant et al., 1987)].

Gypsy moth larvae demonstrated a significant feeding preference for 'Howes' over 'Early Black'. Compounds giving rise to six peaks in the phenolic profile were significantly greater in concentration in 'Early Black' than 'Howes' on at least one of three sampling dates during the growing season. The compounds identified here should be the subject of further investigation to determine their ability to reduce feeding and/or growth of foliage feeders in cranberry. If a feeding deterrent is identified, this deterrent(s) could have potential as a screening method for new cranberry cultivars. As well, breeding schemes and/or cultural practices could be investigated to increase the presence/concentration of the deterrent in cranberry leaves.

\section{Literature Cited}

Averill, A.L. and M.M. Sylvia. 1998. Cranberry insects of the northeast: A guide to identification, biology, and management. Gazette Printing, Easthamptom, MA.

Averill, A.L. and M.M. Sylvia. 2005. Insects, p. 6-18. In: M.M. Sylvia and D. Cannon (eds.). Cranberry 2005 chart book: Management guide for Massachusetts. University of Massachusetts, Amherst, MA. 
Ayres, M.P., T.P. Clausen, S.F. MacLean, A.M. Redman, and P.B. Reichardt. 1997. Diversity of structure and antiherbivore activity in condensed tannins. Ecology 78:1696-1712.

Beninger, C.W. and M.M. Abou-Zaid. 1997. Flavonol glycosides from four pine species that inhibit early instar gypsy moth (Lepidoptera: Lymantriidae) development. Biochem. Syst. Ecol. 25:505-512.

Bryant, J.P., F.S. Chaplin, P.B. Reichardt, and T.P. Clausen. 1987. Response of winter chemical defense in alaska paper birch and green alder to manipulation of carbon/nutrient balance. Oecologia 72:510-514.

Eck, P. 1990. The american cranberry. Rutgers University Press, New Brunswick, NJ.

Kimmins, F.M., D.E. Padgham, and P.C. Stevenson. 1995. Growth inhibition of the cotton bollworm (Helicoverpa armigera) larvae by caffeoylquinic acids from the wild groundnut. Insect Sci. Application 16:363-368.

Lees, D.H. and F.J. Francis. 1971. Quantitative methods for anthocyanins, 6. Flavonols and anthocyanins in cranberries. J. Food Sci. 36: 1056-1060.

Littell, R.C., W.W. Stroup, and R.J. Freund. 2002. SAS for linear models. 4th Ed. SAS Institute, Cary, NC.

Nandutu, A.M., M. Clifford, and N.K. Howell. 2007. Analysis of phenolic compounds in Ugandan sweet potato varieties (NSP, SPK, and TZ). African J. Biochem. Res. 1:29-36.

Ramiro, D.A., O. Guerrerio-Filho, and P. Mazzafera. 2006. Phenol contents, oxidase activities and the resistance of coffee to the leaf miner Leucoptera coffeella. J. Chem. Ecol. 32:1977-1988.

Ranger, C.M., A.P. Singh, J. Johnson-Cicalese, S. Polavarapu, and N. Vorsa. 2007. Intraspecific variation in aphid resistance and constitutive phenolics exhibited by the wild blueberry Vaccinium darrowi. J. Chem. Ecol. 33:711-729.

Simmonds, M.S.J., W.M. Blaney, F. Delle Monache, and G.B. Marini Bettolo. 1990. Insect antifeedant activity associated with compounds isolated from species of Lonchocarpus and Tephrosia. J. Chem. Ecol. $16: 365-380$.

Stevenson, P.C., J.C. Anderson, W.M. Blaney, and M.S.J. Simmonds. 1993. Developmental inhibition of Spodoptera litura (Fab.) larvae by a novel caffeoylquinic acid from the wild groundnut, Arachis paraguariensis (Chod. et Hassl.). J. Chem. Ecol. 19:2917-2933.

Stokes, M.E., C.S. Davis, and G.G. Koch. 1995. Categorical data analysis using the SAS system. SAS Institute, Cary, NC.

Tamura, Y., M. Hattori, K. Konno, Y. Kono, H. Honda, H. Ono, and M. Yoshida. 2004. Triterpenoid and caffeic acid derivatives in the leaves of ragweed, Ambrosia artemisifolia L. as feeding stimulants of Ophraella communa LeSage. Chemoecology 14:113-118.

Vanden Heuvel, J.E. and J.R. Davenport. 2006. Growth and carbon partitioning in cranberry uprights as influenced by nitrogen supply. HortScience 41:1552-1558.

Vvedenskaya, I.O., R.T. Rosen, J.E. Guido, D.J. Russel, K.A. Mills, and N. Vorsa. 2004. Characterization of flavonols in cranberry (Vaccinium macrocarpon) powder. J. Agr. Food Chem. 52:188195.

Vvedenskaya, I.O. and N. Vorsa. 2004. Flavonoid composition over fruit development and maturation in American cranberry, Vaccinium macrocarpon Ait. Plant Sci. 167:1043-1054.

Witzell, J., R. Gref, and T. Nasholm. 2003. Plant-part specific and temporal variation in phenolic compounds of boreal bilberry (Vaccinium myrtilus) plants. Biochem. Syst. Ecol. 31:115-127.

Yan, X., B.T. Murphy, G.B. Hammond, J.A. Vinson, and C.C. Neto. 2002. Antioxidant activities and antitumor screening of extracts from cranberry fruit (Vaccinium macrocarpon). J. Agr. Food Chem. 50: 5844-5849.

Zuo, Y., C. Wang, and J. Zhang. 2002. Separation, characterization and quantitation of benzoic and phenolic antioxidants in american cranberry fruit by GC-MS. J. Agr. Food Chem. 50:3789-3794. 